\title{
BEBERAPA FAKTOR PENENTU KEBERLANJUTAN USAHA AGROINDUSTRI TEH RAKYAT
}

\section{(DETERMINANT FACTORS OF SUSTAINABILITY OF TEA SMALLHOLDER AGROINDUSTRY)}

\author{
Lucyana Trimo $^{1}$, Syarif Hidayat ${ }^{2}$, Muhammad Arief Budiman ${ }^{1}$ \\ ${ }^{1}$ Program Studi Agribisnis Fakultas Pertanian Universitas Padjadjaran \\ ${ }^{2}$ Program Studi Agroteknologi Fakultas Pertanian Universitas Padjadjaran \\ *Corresponding email: lucy.trimo@gmail.com; lucyana.trimo@unpad.ac.id \\ (Diterima 12-10-2018; Disetujui 05-01-2019)
}

\begin{abstract}
ABSTRAK
Saat ini jumlah pelaku agroindustri teh rakyat di Jawa Barat semakin menurun. Sebagai contoh, agroindustri teh rakyat di Kabupaten Cianjur pada tahun 2015 yang terdapat di Kecamatan Sukanagara hanya tinggal enam unit dari 11 unit, Kecamatan Takokak hanya ada 11 unit dari 38 unit, dan Kecamatan Campaka tidak ada lagi agroindustri teh rakyat yang berdiri padahal beberapa tahun yang lalu terdapat tiga unit agroindustri teh rakyat. Kondisi tersebut terjadi juga di daerah lain, seperti di Kecamatan Ciwidey Kabupaten Bandung, saat inipun hanya agroindustri milik Kelompok Tani Barokah yang masih tetap bertahan (dari empat agroindustri yang ada di Kecamatan Ciwidey Kabupaten Bandung). Beberapa faktor penentu tetap bertahannya agroindustri teh rakyat, dapat berasal dari faktor internal maupun eksternal. Teknik penelitian yang digunakan adalah studi kasus. Penentuan informan dilakukan secara purposive yaitu terhadap staf Dinas Perkebunan, ketua dan wakil ketua kelompok tani, general manager agroindustri teh rakyat, petani pemasok, dan perangkat Desa. Data sekunder dikumpulkan dari dokumen yang ada di instansi terkait dan jurnal. Data dan informasi yang diperoleh dianalisis secara deskriptif. Hasil penelitian menunjukan bahwa, keberlanjutan keberadaan usaha agroindustri teh rakyat ditentukan oleh beberapa faktor, yaitu kemampuan pelaku agroindustri teh rakyat dalam: 1) memenuhi persediaan bahan baku (pucuk teh), 2) mengelola keuangan yang dimiliki, 3) mengelola organisasi, 4) melakukan diferensiasi produk, 5) memperluas jaringan informasi dan konektivitas dengan instansi terkait, 6) kontinyuitas dalam memenuhi permintaan pasar, dan 7) kontinyuitas dalam menjaga mutu produk.
\end{abstract}

Kata kunci: agroindustri, daya saing, keberlanjutan, teh rakyat, kontinuitas

\begin{abstract}
At present the number of actors from the tea agro-industry actors in West Java is decreasing, for example, the agroindustry of tea smallholder in Cianjur District in 2015 in Sub-districts: Sukanagara only has six units out of 11 units, Takokak Sub-district there are only 11 units of 38 units, and The Campaka sub-district has no more agroindustry of tea smallholder that was established even though a few years ago there were three units of the agroindustry of tea smallholder. These conditions also occur in other areas, such as in Bandung's Ciwidey District, even now only the Barokah Farmers Group's agroindustry still survives (from the four agroindustries in Bandung's Ciwidey District). Some determinants of the persistence of the agroindustry of tea smallholder can come from internal and external factors concerned. The research technique used is a case study. Determination of informants was done purposively, namely Plantation Service staff, chairman and deputy chairman of the farmer group, general manager of the tea agroindustry of the people, supplier farmers, and village apparatus. Secondary data is collected from existing documents in relevant agencies and journals. Data and information obtained were analyzed descriptively. The results showed that, the sustainability of the existence of the
\end{abstract}


agroindustry of tea smallholder was determined by several factors, namely the ability of the people's tea agro-industry actors in: 1) fulfilling the supply of raw materials (tea tops), 2) managing the finances owned, 3) managing the organization, 4) doing product diversification, 5) expanding information networks and connectivity with relevant agencies, 6) continuity in market demand, and 7) continuity in maintaining product quality.

Keywords: agroindustry, competitiveness, sustainability, tea smallholder, continuity

\section{PENDAHULUAN}

Wilayah Provinsi Jawa Barat yang berpotensi sebagai sentra produksi teh meliputi daerah Cianjur, Tasikmalaya, Sukabumi, Purwakarta, Garut, Bandung, Sumedang dan Subang (Direktorat Jenderal Perkebunan, 2015). Diantara daerah-daerah sentra produksi teh, Kabupaten Bandung merupakan salah satu penghasil teh di Jawa Barat dengan produktivitas yang paling tinggi yaitu mencapai $2.510 \mathrm{~kg} / \mathrm{Ha}$. Hasil produksi Kabupaten Bandung ini mampu melampaui Kabupaten Sukabumi yang memiliki perkebunan rakyat lebih luas yaitu 8.316 ha, namun produktivitasnya hanya mampu menghasilkan $826 \mathrm{~kg} / \mathrm{Ha}$ (Direktorat Jenderal Perkebunan, 2015). Kabupaten Bandung memiliki beberapa agroindustri teh rakyat yang masih berjalan, dan salah satunya berada di Kecamatan Ciwidey. Di kecamatan ini terdapat empat agroindustri teh rakyat, tapi hanya satu yang masih terus bertahan yaitu "Kelompok Tani Barokah".

Pada tahun 2004, petani teh yang berada di Desa Lebak Muncang
Kecamatan Ciwidey berinisiatif untuk membentuk kelompok tani, yaitu "Kelompok Tani Barokah" guna menyalurkan hasil pucuk teh mereka agar tidak dijual ke tengkulak. Setelah dibentuknya kelompok tani, pabrik yang awalnya dikelola oleh individu (H. Wildan) pada akhirnya dikelola secara bersama oleh Kelompok Tani Barokah, sehingga menjadi Agroindustri Teh Rakyat Kelompok Tani Barokah.

Saat ini jumlah anggota anggota Kelompok Tani Barokah sebanyak 26 orang yang dipimpin oleh $\mathrm{H}$. Wildan sebagai ketuanya. Agroindustri teh rakyat Kelompok Tani Barokah memiliki kebun teh seluas $50 \mathrm{Ha}$ yang terdiri atas $45 \mathrm{Ha}$ komoditas teh hijau dan 5 Ha komoditas teh putih. Agroindustri ini merupakan pengolahan teh rakyat yang memiliki kegiatan menghasilkan pucuk teh dari kebun sendiri (milik H. Wildan) maupun dari anggota kelompok tani, untuk kemudian diolah menjadi teh yang sesuai dengan keinginan pasar. Saat ini, produk teh yang diproduksi oleh agroindustri teh 
rakyat Kelompok Tani Barokah memiliki merek Pucuk Sari.

Lahan teh yang dikelola Kelompok Tani Barokah secara keseluruhan adalah 50 Ha, dengan rata-rata 10.000 pohon/Ha, dimana $20 \mathrm{Ha}$ adalah lahan milik pribadi dan $30 \mathrm{Ha}$ merupakan milik anggota Kelompok Tani Barokah. Dari luas kebun yang ada 45 ha ditanami oleh teh hijau dengan klon TRI 2024, dan sisanya seluas $5 \mathrm{Ha}$ ditanami teh putih dengan klon GMB (Gambung) 7. Beberapa produk yang dihasilkannya adalah teh hijau dan teh putih dengan merek Pucuk Sari.

Pengembangan produk hilir teh bernilai tambah tinggi akan mampu meningkatkan nilai ekonomis teh Indonesia, khususnya teh yang berasal dari perkebunan rakyat. Hal tersebut merupakan salah satu alternatif untuk meningkatkan harga jual teh rakyat, yang akhirnya dapat meningkatkan pendapatan petani teh dan akan berdampak terhadap keberlangsungan hidup agroindustri teh rakyat. Tetapi, dalam pengembangannya, agroindustri teh rakyat mengalami berbagai macam permasalahan, tak terkecuali Kelompok Tani Barokah.

Agroindustri teh rakyat yang dikelola oleh Kelompok Tani Barokah ini mengalami berbagai macam permasalahan, misalnya ketersediaan pucuk teh, kurangnya mesin pengolah yang dibutuhkan untuk mengembangkan usahanya, belum adanya Standar Operasional Prosedur (SOP), keterbatasan biaya produksi, keterbatasan pemasaran, masih kurangnya fasilitasi pemerintah terhadap pengembangan agroindustri teh rakyat, dan belum terintegrasinya pembinaan yang dilakukan pemerintah mulai dari on-farm sampai ke off-farm. Tetapi walaupun demikian, agroindustri teh rakyat yang dikelola oleh Kelompok Tani Barokah masih tetap bertahan untuk terus diusahakan. Oleh karena itu, perlu diketahui faktor-faktor penentu apa saja yang menyebabkan Kelompok Tani Barokah masih berkelanjutan.

\section{METODE PENELITIAN}

Desain penelitian yang digunakan pada penelitian ini adalah desain penelitian deskriptif kualitatif. Sugiyono (2012) menyatakan bahwa penelitian kualitatif adalah penelitian yang berlandaskan pada filsafat postpositivisme, digunakan untuk meneliti pada kondisi objek yang alamiah, dimana peneliti adalah sebagai instrumen kunci. Penggunaan pendekatan deskriptif kualitatif karena penelitian ini merupakan 
studi kasus yang melihat banyak variabel yang harus diperhatikan untuk mendapatkan gambaran dan keterangan-keterangan mengenai objek penelitian. Penentuan informan dilakukan secara purposive yaitu terhadap staf Dinas Perkebunan, ketua dan wakil ketua kelompok tani, general manager agroindustri teh rakyat, petani pemasok, dan perangkat Desa. Data sekunder dikumpulkan dari dokumen yang ada di instansi terkait dan jurnal. Data dan informasi yang diperoleh dianalisis secara deskriptif. Untuk memeriksa keabsahan data maka digunakanlah teknik triangulasi. Menurut Sugiyono (2012), triangulasi merupakan teknik pemeriksaan keabsahan atau kredibilitas data yang bersifat menggabungkan dari berbagai teknik pengumpulan data dan sumber data yang telah ada. Triangulasi dilakukan dengan menggunakan teknik yang berbeda yaitu wawancara mendalam, observasi partisipatif dan dokumen.

\section{HASIL DAN PEMBAHASAN}

$\begin{array}{lrr}\text { Faktor } & \text { Internal } & \text { Penentu } \\ \text { Keberlanjutan } & \text { Usaha } & \text { Agroindustri } \\ \text { Teh Rakyat } & & \end{array}$

\section{Kondisi kelompok \\ organisasi/dinamika}

Sumberdaya manusia yang dimiliki oleh Kelompok Tani Barokah saat ini berjumlah 62 orang, terdiri atas karyawan pabrik 17 orang, karyawan kebun kurang lebih 37 orang, dan karyawan kantor sebanyak 8 orang yang terdiri atas general manager, staf administrasi, kepala pabrik, kepala kebun, satpam, sopir dan mandor petik. Selanjutnya, jumlah penduduk Desa Lebak Muncang yang menjadi anggota Kelompok Tani Barokah sebanyak 62 orang. Selain itu agroindustri teh rakyat ini mampu menyerap 2,05\% sumber daya manusia, dari keseluruhan jumlah persentase penduduk $(60,24 \%)$ desa Lebak Muncang yang bermatapencaharian sebagai petani.

Sumberdaya manusia yang berada di agroindustri teh rakyat untuk karyawan kebun rata-rata berumur 45 tahun dan karyawan pabrik rata-rata berumur 35 tahun. Tingkat pendidikan sumberdaya manusia yang bekerja pada agroindustri teh rakyat ini, rata-rata berpendidikan setingkat SD, bahkan ada yang tidak menyelesaikan sekolah dasarnya, dan sedikit karyawan yang memiliki pendidikan sampai SMP, apalagi SMA.

Kelompok Tani Barokah dalam menjalankan usahanya memiliki misi mengutamakan atmosfer kekeluargaan dalam bekerja dan bekerjasama. Suasana kekeluargaan pun diciptakan oleh 
perusahaan ini agar hubungan dengan para pekerja tetap harmonis tanpa melihat latar belakang dari pekerja tersebut. Sistem kekeluargaan yang diterapkan oleh agroindustri teh rakyat ini merupakan suatu keuntungan, karena komunikasi antar sumberdaya manusia terjalin dengan baik. Waktu kerja setiap pekerja mulai pukul 07.00 WIB hingga pukul 16.00 WIB. Upah yang diberikan kepada karyawan pabrik adalah upah dengan sistem borongan.

Namun, dalam pelaksanaan kegiatan pengolahan, Kelompok Tani Barokah belum berpegangan pada SOP yang merupakan panduan pelaksanaan, yang terdiri atas tahap-tahap tindakan dan digunakan dalam mengimplementasikan tindakan tersebut secara terstruktur. Mereka beranggapan bahwa tanpa adanya SOP, baik secara tertulis maupun tidak tertulis, para pekerja sudah memahami masing-masing tugasnya. Mereka belum menyadari pentingnya SOP untuk menjaga kekonsistenan dan kontinuitas kualitas serta kuantitas dari produk yang dihasilkannya. SOP secara tertulis seharusnya tersedia di agroindustri teh rakyat ini, hal tersebut dilakukan agar dapat menyediakan sebuah informasi yang konsisten kepada para pekerja dalam menjalankan setiap kegiatan produksi yang berlangsung.

\section{Kemampuan mesin olah}

Kapasitas terpasang mesin olah yang dimiliki Kelompok Tani Barokah, yaitu 7 ton per hari (pucuk basah), sedangkan kapasitas terpakai mesin tersebut yaitu 5 ton per hari. Hal itu dilakukan oleh agroindustri teh ini untuk tetap menjaga ketahanan mesin agar tidak mudah rusak. Salah satu penyebab agroindustri ini belum bisa melakukan ekspor dikarenakan jumlah mesin pengolahannya masih terbatas. Hal ini terlihat dari ketersediaan mesin olah yang hanya satu unit dan hanya bisa menghasilkan $250 \mathrm{~kg} / \mathrm{hari}$ teh hijau, sedangkan berdasarkan pernyataan dari wakil ketua Kelompok Tani Barokah, untuk memenuhi permintaan ekspor harus mempunyai dua unit mesin.

\section{Kemampuan dalam membiayai kegiatan produksi}

Modal merupakan hal yang diperlukan dalam setiap kegiatan usaha termasuk pada agroindustri teh rakyat. Permodalan yang dimiliki Kelompok Tani Barokah masih terbatas pada modal sendiri. Pada awal pembentukan usaha, agroindustri ini pernah meminjam ke 
bank. Uang ini dijadikan sebagai modal untuk investasi dan modal kerja. Setelah itu sebagian besar hanya mengandalkan modal sendiri dan tidak adanya pemberian bantuan modal yang diberikan oleh pemerintah. Saat ini modal yang digunakan oleh agroindustri teh rakyat Kelompok Tani Barokah bersumber dari modal sendiri dari para anggotanya. Kelompok tani ini melakukan pengolahan melalui koperasi dan modalnya berasal dari iuran. Keuangan yang ada di agroindustri ini digunakan untuk modal membeli bahan baku (pucuk teh). Adapun harga pucuk teh yang dibayarkan secara tunai kepada petani berkisar antara
Rp 2.300 sampai dengan $R p 2.400$ setiap kg. Harga ini pun berlaku untuk pemasok selain anggota kelompok tani Barokah.

Saat ini, Kelompok Tani Barokah dihadapkan pada permasalahan biaya produksi yang terus meningkat. Hal ini menjadi penyebab menurunnya pendapatan yang mereka peroleh. Meningkatnya biaya produksi disebabkan oleh adanya perubahan musim. Pada saat musim kemarau tiba, jumlah pucuk teh yang merupakan bahan baku industri teh dalam kondisi menurun, selain itu harga pucuk teh menjadi mahal. Kondisi biaya produksi dan pendapatan Kelompok Tani Barokah, dapat dilihat dalam Tabel 1.

Tabel 1. Data Biaya dan Pendapatan Agroindustri Teh Rakyat Kelompok Tani Barokah 2017

\begin{tabular}{rlrrrrr}
\hline No. & Bulan & $\begin{array}{c}\text { Fix Cost } \\
(\text { FC) }\end{array}$ & $\begin{array}{c}\text { Variable Cost } \\
(\text { VC) }\end{array}$ & $\begin{array}{c}\text { Biaya total } \\
(\mathbf{R p})\end{array}$ & $\begin{array}{c}\text { Pendapatan } \\
(\mathbf{R p})\end{array}$ & Benefit (Rp) \\
\hline 1 & Januari & 5.250 .000 & 396.802 .427 & 402.052 .427 & 345.870 .775 & -56.181 .652 \\
2 & Februari & 5.250 .000 & 176.136 .325 & 181.386 .325 & 204.867 .150 & 23.480 .825 \\
3 & Maret & 5.250 .000 & 192.824 .266 & 198.074 .266 & 215.493 .650 & 174.19 .384 \\
4 & April & 5.250 .000 & 332.665 .204 & 337.915 .204 & 365.265 .700 & 27.350 .496 \\
5 & Mei & 5.250 .000 & 291.292 .693 & 296.542 .693 & 317.440 .157 & 20.897 .464 \\
6 & Juni & 5.250 .000 & 340.183 .581 & 345.433 .581 & 256.284 .775 & -89.148 .806 \\
7 & Juli & 5.250 .000 & 301.591 .835 & 306.841 .835 & 366.831 .000 & 59.989 .165 \\
8 & Agustus & 5.250 .000 & 258.186 .067 & 263.436 .067 & 266.310 .375 & 2.874 .308 \\
9 & September & 5.250 .000 & 203.229 .919 & 208.479 .919 & 264.482 .500 & 56.002 .581 \\
10 & Oktober & 5.250 .000 & 189.303 .585 & 194.553 .585 & 234.292 .075 & 39.738 .490 \\
11 & November & 5.250 .000 & 359.880 .735 & 365.130 .735 & 328.402 .125 & -36.728 .610 \\
12 & Desember & 5.250 .000 & 358.146 .328 & 363.396 .328 & 412.316 .475 & 48.920 .147 \\
\hline & Total & 63.000 .000 & 3.400 .242 .965 & 3.463 .242 .965 & 3.577 .857 .757 & 114.614 .792 \\
\hline
\end{tabular}

Sumber: Agroindustri Teh Rakyat Kelompok Tani Barokah, diolah (2017)

Ketidakstabilan usaha pada agroindustri rakyat Kelompok Tani Barokah dapat dilihat dari berfluktuasinya hasil total cost (TC) dan total revenue (TR) setiap bulannya. Pada bulan Januari, Juli dan November terlihat bahwa TR lebih rendah daripada $\mathrm{TC}$, hal ini terjadi akibat menurunnya penjualan teh hijau olahan 
agroindustri teh rakyat Kelompok Tani Barokah yang disebabkan oleh permintaan pasar yang sedang berkurang. Saat pendapatan bernilai negatif atau terjadi kerugian, biasanya Kelompok Tani Barokah menggunakan dana cadangan yang berasal dari simpanan hasil keuntungan, atau pinjaman kepada ketua kelompok tani Barokah yaitu $\mathrm{H}$. Wildan. Jika dihitung BC rationya, maka diperoleh nilai 1,033. Nilai ini kecil, akan tetapi karena dikelola berdasarkan kebersamaan dan jalinan kekeluargaan yang kuat, maka Kelompok Tani Barokah masih dapat bertahan untuk terus diusahakan.

\section{Faktor Eksternal Penentu Keberlan- jutan Usaha Agroindustri Teh Rakyat}

\section{Permintaan pasar}

Kelompok Tani Barokah menghasilkan beberapa jenis produk olahan, yaitu teh hijau dan teh putih. Beberapa jenis teh tersebut memiliki target dan permintaan pasar yang berbeda-beda. Proses pemasaran yang dilakukan oleh agroindustri ini dilakukan hanya dengan cara dari mulut ke mulut. Khusus untuk teh putih, pemasaran pada awalnya melalui bazar sabtu minggu yang diadakan di Masjid Istiqomah. Para pembelinya yaitu jemaah yang datang dari Pekanbaru dan Nusa Tenggara Barat.

Sedangkan untuk teh hijau, pelanggan Kelompok Tani Barokah berasal dari Jawa Tengah, Cirebon dan Bandung. Bentuk penjualan produk kepada pelanggan dengan sistem kepercayaan. Daftar pelanggan yang rutin membeli teh hijau hasil olahan agroindustri teh rakyat Kelompok Tani Barokah dapat dilihat pada Tabel 2. Dari tabel tersebut terlihat bahwa pelanggan dari Jawa Tengah dan Cirebon paling banyak memesan produk teh olahan dengan jenis second grade dari Kelompok Tani Barokah.

Tabel 2. Daftar Pelanggan rutin (Packer) agroindustri teh rakyat Kelompok Tani Barokah, dan Rerata Orderan per Satu kali Pengiriman

\begin{tabular}{clccc}
\hline No & \multicolumn{1}{c}{ Pelanggan } & Alamat & Jenis Olahan & Kuantitas \\
\hline 1 & Sepeda Balap & Jawa Tengah & Second Grade & $5000 \mathrm{~kg}$ \\
2 & Cap Jangkar & Cirebon & Second Grade & $5000 \mathrm{~kg}$ \\
3 & Dungus Wangi & Bandung & Second Grade & $200 \mathrm{~kg}$ \\
4 & Pucuk Bola & Bandung & First Grade & $500 \mathrm{~kg}$ \\
5 & Peko Super & Bandung & First Grade & $100 \mathrm{~kg}$ \\
\hline
\end{tabular}

Sumber : Agroindustri Teh Rakyat Kelompok Tani Barokah, 2017

Selain memproduksi produk olahan teh hijau, agroindustri ini mulai melaku- kan pengembangan dengan memproduksi teh putih dalam skala kecil. Saat ini 
agroindustri teh rakyat Kelompok Tani Barokah baru mampu memproduksi teh putih sebanyak $20 \mathrm{~kg} / \mathrm{bulan}$. Hal itu dikarenakan bahan baku pucuk teh yang digunakannya belum banyak. Selain itu, proses pengeringannya yang menggunakan sinar matahari langsung agar kualitasnya baik, membuat proses produksinya lebih lama dibandingan dengan proses produksi teh hijau. Harga jual teh putih tersebut adalah $\mathrm{Rp}$ $1.500 .000 / \mathrm{kg}$ atau $\mathrm{Rp} 150.000 / \mathrm{gr}$ yang dijual langsung kepada konsumen akhir. Kelompok Tani Barokah telah mempunyai langganan tetap untuk teh putihnya, yaitu pemerintah daerah seperti Dinas Koperasi, Dinas Perkebunan. Bupati Kabupaten Bandung menjadikan teh putih dari agroindustri ini sebagai cindera mata. Jepang pernah memesan sebanyak 500 kg/bulan namun kelompok tani ini menyerah karena setelah bekerja sama dengan Gambung masih tidak bisa mencukupi pesanannya dan hanya mampu menghasilkan $250 \mathrm{~kg} / \mathrm{bulan}$.

\section{Ketersediaan pucuk teh}

Agroindustri teh rakyat ini mendapatkan pasokan dari para petani yang tergabung dalam Kelompok Tani Barokah, juga pasokan dari luar kelompok tani. Untuk mengetahui jumlah produksi pucuk teh basah dan pucuk teh kering pada tahun 2013-2017 dapat dilihat pada Gambar 1.

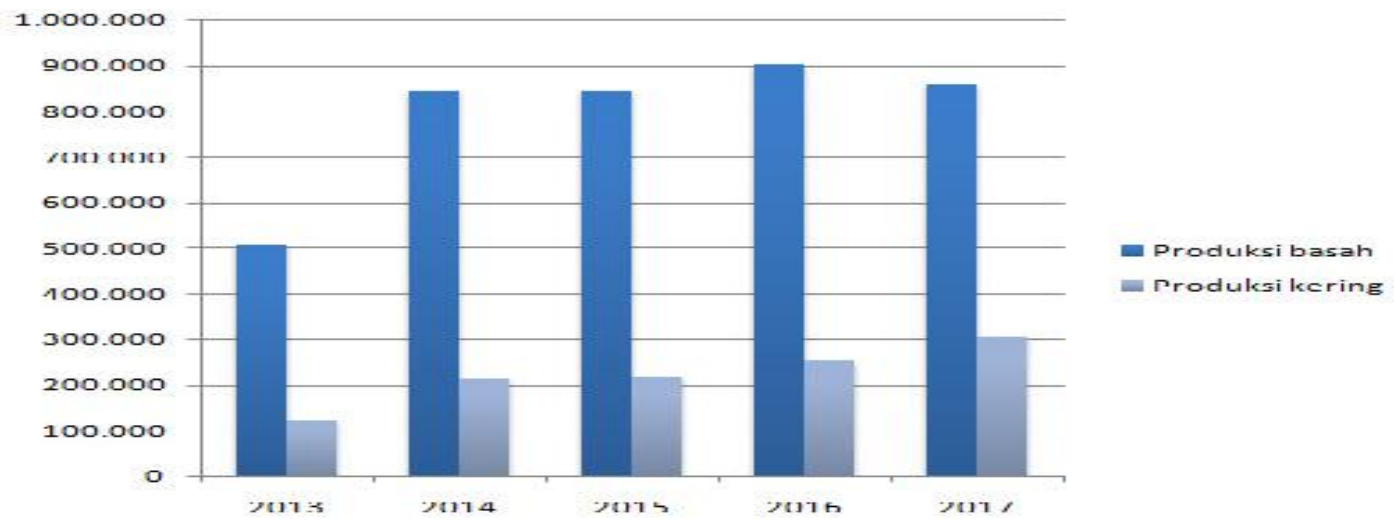

Gambar 1. Jumlah Produksi Pucuk Teh Basah dan Pucuk Teh kering pada Tahun 20132017

Sumber: Agroindustri Teh Rakyat Kelompok Tani Barokah, 2017

Gambar 1 memperlihatkan bahwa jumlah produksi pucuk teh basah dan pucuk teh kering pada tahun 2013-2017 mengalami fluktuatif. Penurunan dan peningkatan hasil produksi pucuk teh yang berfluktuatif merupakan dampak dari kurangnya persediaan bahan baku. 
Pasokan bahan baku berupa pucuk teh merupakan faktor yang paling penting bagi agroindustri teh rakyat. Pucuk teh ini didapatkan $30 \%$ dari petani anggota Kelompok Tani Barokah, dan $40 \%$ dari non anggota kelompok tani. Selain itu, agroindustri ini membeli teh keringan dari luar sebanyak $30 \%$ atau $25-30$ ton/bulan, jumlah ini tergantung pada cuaca. Agroindustri ini membeli pucuk teh dari luar kelompok tani atau dari pengumpul (ada tiga bandar yang memasok bahan baku), yaitu sebanyak $40 \%$ atau 40-60 ton/bulan. Petani luar memasok ke agroindustri ini karena mereka tidak melakukan kegiatan pasca panen atau pengolahannya. Pucuk teh yang dipasok ke agroindustri ini harus mempunyai mutu dan kualitas bagus dengan standar pucuk medium, artinya pucuk dan batangnya tidak terlalu panjang. Selama ini petani telah mengetahui standar pucuk yang medium untuk dipasok, sehingga agroindustri teh ini mendapatkan bahan baku berupa pucuk teh yang sesuai dengan keinginan.

Hubungan yang terjadi antara agroindustri teh rakyat Kelompok Tani Barokah dengan pemasok adalah kerjasama dalam pengadaan bahan baku pucuk teh yang dibutuhkan dalam kegiatan produksi. Hubungan yang terjalin antara agroindustri dengan pemasok dapat dikatakan sangat baik, hal ini dikarenakan pekerjaan yang dilakukan didasari oleh rasa saling percaya dan kekeluargaan sesuai dengan misi agroindustri teh rakyat Kelompok Tani Barokah yang mengutamakan rasa kekeluargaan, sehingga terbentuk rasa saling percaya.

Hubungan kerjasama yang terjadi antara agroindustri teh rakyat Kelompok Tani Barokah dengan para petani yang tergabung dalam Kelompok Tani Barokah merupakan hubungan timbal balik dalam mewujudkan kerjasama agar kedua belah pihak saling diuntungkan. Jumlah anggota Kelompok Tani Barokah adalah sebanyak 26 anggota dengan total luas kebun teh seluas 50 Ha. Selain itu, agroindustri ini juga menjalin hubungan kerjasama dengan non anggota atau para petani teh di luar Kelompok Tani Barokah kurang lebih sebanyak 10 orang. Cara yang dilakukan agroindustri ini untuk mengikatnya yaitu dengan memberikan pinjaman pupuk, obat ataupun transportasi yang pembayarannya akan dipotong setelah panen, baik tunai ataupun dicicil. Pemasok memberikan pasokan bahan baku berupa pucuk teh dengan standar pucuk medium yang kontinu. 
Walaupun pengadaannya cukup mudah, namun selama ini agroindustri teh rakyat Kelompok Tani Barokah masih belum dapat memenuhi kebutuhan bahan baku untuk kegiatan produksinya, apalagi di musim kemarau.

Tabel 3. Jumlah Produksi Pucuk Teh Basah dan Pucuk Teh kering pada Tahun 2017

\begin{tabular}{clcc}
\hline \multirow{2}{*}{ No } & \multirow{2}{*}{ Bulan } & \multicolumn{2}{c}{ Jumlah Produksi $($ Kg) } \\
\cline { 3 - 4 } & & Basah & Kering \\
\hline 1 & Januari & 92.093 & 21.821 \\
2 & Februari & 33.866 & 7.983 \\
3 & Maret & 45.615 & 11.019 \\
4 & April & 96.493 & 22.016 \\
5 & Mei & 75.695 & 17.360 \\
6 & Juni & 86.942 & 20.143 \\
7 & Juli & 83.969 & 19.576 \\
8 & Agustus & 67.381 & 16.370 \\
9 & September & 46.811 & 11.391 \\
10 & Oktober & 51.091 & 12.174 \\
11 & November & 98.924 & 23.065 \\
12 & Desember & 78.684 & 18.545 \\
\hline & Jumlah & 858.364 & 201.454 \\
\hline
\end{tabular}

Sumber: Agroindustri Teh Rakyat Kelompok Tani Barokah, 2017

Berdasarkan Tabel 3 terlihat bahwa pasokan pucuk dari petani selama kurun waktu 2013-2017 jumlahnya berfluktuatif. Jumlah produksi teh dibagi menjadi dua jenis produksi, yaitu produksi pucuk basah dan produksi pucuk kering. Pucuk teh basah yang akan diolah beratnya akan menyusut dengan perbandingan 4:1 yang artinya setiap $4 \mathrm{~kg}$ pucuk teh basah apabila diolah menjadi teh kering hanya menghasilkan sebanyak $1 \mathrm{~kg}$. Rata-rata pucuk teh basah yang dihasilkan oleh
Kelompok Tani Barokah adalah 71 ton/bulan yang artinya rata-rata tiap anggota menghasilkan 3 ton/bulan. Peningkatan dan penurunan jumlah produksi teh kering selalu terjadi karena disebabkan oleh keadaan musim. Untuk mengatasi kesulitan dalam memperoleh pucuk teh, maka agroindustri ini membeli teh keringan yang belum disortir dari pabrik lain yang kualitasnya teh keringannya setara. Hal ini dilakukan untuk memenuhi kebutuhan konsumen.

Pembelian pucuk teh atau teh keringan yang belum disortir ini dilakukan agar proses produksinya tidak terganggu sehingga tetap dapat melakukan kegiatan produksi. Selain itu, pembelian ini bertujuan agar dapat memenuhi permintaan pelanggan atau konsumen. Agroindustri teh rakyat Kelompok Tani Barokah membeli pucuk teh sebanyak 80-90 ton/bulan.

Berdasarkan Tabel 4, terlihat bahwa Agroindustri Teh Rakyat Kelompok Tani Barokah melakukan pembelian teh kering setiap bulannya sebanyak $30 \%$ teh keringan dari pabrik lain atau rata-rata membeli sebanyak $8.792 \mathrm{~kg} / \mathrm{bulan}$. Hal tersebut dikarenakan pasokan pucuk teh dari petani masih kurang. Apabila terjadi kekurangan bahan baku, maka pasokan diperoleh dari Cukul 
yang berada di Pangalengan Bandung, Garut, Cianjur, dan Sukabumi.

Tabel 4. Jumlah Pasokan Pucuk teh dan Jumlah Pembelian Teh Keringan pada Tahun 2017

\begin{tabular}{lcccc}
\hline \multicolumn{1}{c}{ Bulan } & $\begin{array}{c}\text { Pasokan pucuk teh } \\
\text { dari petani }(\mathbf{K g})\end{array}$ & $\begin{array}{c}\text { Jumlah Produksi } \\
\text { Kering }(\mathbf{K g})\end{array}$ & $\begin{array}{c}\text { Jumlah pembelian } \\
\text { teh kering dari } \\
\text { pabrik lain }(\mathbf{K g})\end{array}$ & $\begin{array}{c}\text { Jumlah } \\
\text { permintaan }(\text { Kg) }\end{array}$ \\
\hline Januari & 92.093 & 21.821 & 10.929 & 32.750 \\
Februari & 33.866 & 7.983 & 12.611 & 20.594 \\
Maret & 46.615 & 11.019 & 11.457 & 22.476 \\
April & 96.493 & 22.016 & 11.643 & 33.659 \\
Mei & 75.595 & 17.360 & 10.455 & 27.815 \\
Juni & 86.942 & 20.143 & 7.922 & 28.065 \\
Juli & 83.969 & 19.576 & 8.164 & 27.740 \\
Agustus & 67.381 & 16.370 & 1.085 & 17.455 \\
September & 46.811 & 11.391 & 2.580 & 13.971 \\
Oktober & 51.091 & 12.174 & 5.879 & 18.053 \\
November & 98.924 & 23.065 & 6.101 & 29.166 \\
Desember & 78.584 & 18.545 & 16.684 & 35.229 \\
\hline Total & 858.360 & 201.454 & 105.510 & 306.793 \\
\hline
\end{tabular}

Sumber: Agroindustri Teh Rakyat Kelompok Tani Barokah, 2017

Pengadaan bahan baku yang mudah diperoleh berasal dari anggota kelompok tani, hal ini terlihat dari pasokan bahan baku berupa pucuk teh dengan standar pucuk medium yang secara kontinu dipasok. Berapapun jumlah pasokan dari petani baik dalam jumlah banyak atau sedikit tetap diterima oleh Kelompok Tani Barokah.

\section{Fasilitasi dari Pemerintah}

Fasilitasi dari pemerintah yang pernah diperoleh Kelompok Tani Barokah, salah satunya adalah bantuan program intensifikasi pada tahun 2014 berupa pemberian bibit dan obat. Selanjutnya, pada tahun 2015 mereka mendapatkan program hibah dari Dinas Perkebunan Kabupaten Bandung berupa 8.000 bibit pengganti dan saprodi berupa power sprayer. Sedangkan untuk bantuan bagi pengembangan pabrik, Kelompok Tani Barokah belum pernah mendapatkannya. Program bantuan banyak diberikan untuk kebun teh saja. Selain itu, terdapat pula bentuk kerjasama berupa bantuan sarana produksi dan juga fasilitasi promosi dalam bentuk pameran.

Hubungan yang terjaga secara kontinu antara agroindustri teh rakyat Kelompok Tani Barokah dengan Dinas Perkebunan membuat agroindustri ini tidak kesulitan untuk mengakses informasi mengenai kegiatan pameran. Selain itu, dengan adanya bantuan promosi dapat membantu memperkenalkan produk hasil olahan agroindustri teh rakyat kepada pasar yang lebih luas. Adanya bantuan dari lembaga pemerintah seperti Dinas Perkebunan Jawa Barat 
maupun Dinas Perkebunan Kabupaten Bandung menjadi salah satu faktor pendorong bagi agroindustri teh rakyat Kelompok Tani Barokah untuk tetap bertahan hingga saat ini.

\section{Pesaing}

Pesaing dari agroindustri teh rakyat Kelompok Tani Barokah di kawasan Ciwidey adalah agroindustri sejenis yang memasarkan produk mereka ke pasar yang sama. Di Kecamatan Ciwidey sendiri, sebenarnya terdapat 4 (empat) agroindustri teh rakyat antara lain pabrik di Rawabogo yaitu CV Gunung Padang, pabrik di Rancagede yaitu Tjiwangi, pabrik di Cilastri dan agroindustri teh rakyat Kelompok Tani Barokah. Dari ke 4 (empat) pabrik tersebut, ada dua pabrik yang sudah total tidak dapat melakukan produksi, yang satu lagi sudah jarang berproduksi, dan satu-satunya yang masih berjalan yaitu agroindustri teh rakyat Kelompok Tani Barokah. Pabrik yang berada di Rawabogo dan Rancagede sudah total tidak berproduksi karena kedua pabrik tersebut tidak memiliki kebun sendiri sehingga tidak adan bahan baku yang dapat diolah.

Agroindustri teh rakyat Kelompok Tani Barokah dapat bertahan hingga sekarang karena mempunyai kebun sendiri, sehingga dapat mempertahankan produksi. Intensitas persaingan dalam pasar cukup ketat, karena saat ini muncul pendatang baru yang membawa kapasitas baru dan inovasi baru. Salah satu pendatang baru di Kecamatan Ciwidey yang menjadi pesaing baru bagi Agroindustri teh rakyat Kelompok Tani Barokah adalah Pabrik Teh Kartini Nasional yang berada di Kecamatan Pasir Jambu. Agroindustri tersebut membeli pucuk teh dari petani dengan harga lebih tinggi, dan menawarkan produk serupa di pasaran; namun bedanya pabrik baru tersebut belum melakukan diferensiasi produk dan hanya menjual teh keringan.

Hal yang dilakukan oleh agroindustri teh rakyat Kelompok Tani Barokah untuk tetap dapat bersaing dan mempertahankan eksistensi produknya dalam menghadapi pesaing yaitu dengan melakukan diferensiasi produk, segmentasi pasar dan tetap memproduksi olahan teh sesuai dengan keinginan pelanggan maupun konsumen.

Selain itu, mempertahankan kualitas produk agar tetap berdaya saing merupakan strategi agroindustri teh rakyat Kelompok Tani Barokah, yaitu dengan cara melakukan sortasi atau pengelompokan jenis teh terhadap produk teh olahannya. Hal tersebut dilakukan 
untuk dapat menyesuaikan dengan kebutuhan konsumen. Kelompok Tani Barokah memiliki prinsip, bahwa persaingan yang harus dihadapi berawal dari proses pengadaan bahan baku hingga kegiatan pemasaran. Persaingan juga menuntut agroindustri teh rakyat Kelompok Tani Barokah ini untuk tetap dapat memenuhi kebutuhan konsumen walaupun pada saat kekurangan bahan baku.

\section{KESIMPULAN}

Keberlanjutan keberadaan usaha agroindustri teh rakyat ditentukan oleh beberapa faktor, yaitu kemampuan pelaku agroindustri teh rakyat dalam: 1) memenuhi persediaan bahan baku (pucuk teh), 2) mengelola keuangan yang dimiliki, 3) mengelola organisasi, 4) melakukan diferensiasi produk, 5) memperluas jaringan informasi dan konektivitas dengan instansi terkait, 6) kontinuitas dalam memenuhi permintaan pasar, dan 7) kontinuitas dalam menjaga mutu produk.

\section{UCAPAN TERIMAKASIH}

Terimakasih yang sebesar-besarnya kepada Rektor Universitas Padjadjaran dan DRPMI Universitas Padjadjaran atas pembiayaan penelitian ini melalui program Hibah Internal Unpad (Riset Kompetensi Dosen Unpad).

\section{DAFTAR PUSTAKA}

Badan Pusat Statistik. 2017. Kecamatan Ciwidey dalam Angka 2017. BPS Kabupaten Bandung.

Bisnis Indonesia. 23 September 2013. Jabar Siap Revitalisasi Kebun Teh. (http://epaper.bisnis.com/)

Dinas Perkebunan Jawa Barat. 2006. Inventarisasi Pendapatan/Daya Beli Petani Pada Perkebunan Rakyat Di Provinsi Jawa Barat.

Dinas Perkebunan Jawa Barat. 2014. Kajian Pengembangan Kawasan Agribisnis Teh Rakyat Di Provinsi Jawa Barat.

Direktorat Jenderal Perkebunan, 2015.Statistik Perkebunan Indonesia 2014-2016 Teh.

Direktorat Tanaman Tahunan dan Penyegar, Direktorat Jenderal Perkebunan Kementerian Pertanian, 2015. Pengembangan Agribisnis Teh 2016-2045. Jakarta.

Fakultas Pertanian UNPAD dan Dinas Perkebunan Provinsi Jawa Barat. $2006 . \quad$ Inventarisasi Pendapatan/Daya Beli Petani Pada Perkebunan Rakyat Di Provinsi Jawa Barat.

Forum Sertifikasi Teh Indonesia. 2010. Good Agricultural Practices. Newsletter Sustainable Tea. Edisi September-Oktober 2010.

Gusti, I Bagus Udayana. 2011. Peran Agroindustri Dalam Pembangunan Pertanian. Penerbit Singhadwala.

International Tea Committee. 2015. Annual Bulletin of Statistics 2015. International Tea Committee, London

Lucyana Trimo, Rohayati Suprihatini, Kralawi Sita, Shabri dan Hilman Maulana. 2015. Pengujian Produk 
BEBERAPA FAKTOR PENENTU KEBERLANJUTAN USAHA AGROINDUSTRI TEH RAKYAT

Lucyana Trimo, Syarif Hidayat, Muhammad Arief Budiman

dan Pasar Tepung Teh Sebagai

Bahan Baku Industri Minuman,

Makanan dan Biofarmaka Di Jawa

Barat. BP3IPTEK dan UNPAD. 